\title{
The Role of NS Personality and Experience in NS-NNS Interaction
}

Tracey M. Derwing

This study investigates the relationship of native speakers' (NSs) personality traits and experience interacting with non-native speakers (NNSs) to the use of conversational adjustments and differences in word frequency and speech rate. Eight ESL instructors and eight persons who had no regular contact with NNSs were asked to view a film, then tell a NS and a NNS partner its story. Transcripts of the subjects' film narratives to the listeners were examined for differences in word frequency, rate, and conversational

\begin{abstract}
adjustments.
Although the ESL instructors used certain conversational adjustments significantly more with NNSs than did the inexperienced subjects, the two groups did not differ in terms of word frequency or rate. When subjects were grouped according to the personality traits of interpersonal affect and social participation, they did not differ in overall usage of conversational adjustments, but significant differences were found in both word frequency and speech rate.
\end{abstract}

An incident which occurred while I was teaching ESL to recent immigrants was the catalyst for this study. On the evening in question, a colleague who taught beginners took into class the front page of a newspaper, the headline of which read BUS STRIKE STARTS AT MIDNIGHT. She spent approximately 45 minutes discussing the strike with her class, explaining carpools and the acceptability of hitchhiking during a transportation strike, rehearsing work and home addresses, etc. Since many of the students depended on the bus to get to work, and since none had anything but the most rudimentary knowledge of English, this information was not only timely, but extremely important to them. After class, another individual who was teaching an intermediate level course expressed incredulity: 'How did you tell the beginners about the bus strike? I didn't say anything to my students. I didn't know how I could possibly explain a strike to them.'

I wondered how long her students would wait for the bus the next morning in the $-35^{\circ} \mathrm{C}$ weather. I also wondered why one person felt no hesitation in explaining information necessary to her students, regardless of their extremely limited English, while another avoided the subject altogether for fear of being unable to express it adequately, despite the fact that her class had a good grasp of basic English.

That some people appear to be more successful in communicating a message to NNSs than others is unremarkable. As with any other verbal skill, there is bound to be individual variation, both in 
terms of conversational and input adjustments and ultimate success. In addition, factors such as features of the NNS (e.g., comprehension level and accent), relative knowledge of the discourse domain and familiarity with the interlocutor all affect NS linguistic behaviour (Warren-Leubecker \& Bohannon 1982, Zuengler 1989, Gaies 1982). The issue of interpersonal differences gains importance, however, if significant differences are not entirely idiosyncratic, but are characteristic of individuals who belong to specific groups. For instance, it has been suggested that warm, outgoing people sensitive to the emotional state of the learner are at the very least perceived by students as better teachers (Larkin 1987, Moscowitz 1978, Stevick 1974). Gass \& Varonis (1984) have shown that ESL teachers are better able to understand NNS speech than are inexperienced NSs, although they did not compare ESL instructors' and other NSs' own production. This study investigates differences in the use of adjustments made for NNS listeners when subjects are grouped according to personality type, specifically high interpersonal affect and social participation vs. low interpersonal affect and social participation. ${ }^{1}$ The role of experience (ESL instructors versus inexperienced NSs) will also be addressed.

There have apparently been no large-scale investigations which attempt to relate ESL teachers' personality traits to successful NS-NNS communication. Although numerous coding systems for documenting classroom interaction have been developed, they have proven to be inadequate in that they describe teachers' behaviours in terms of pedagogical function alone (see Long, 1980b for a comprehensive critique of interaction analysis). One of the few studies that specifically examined the connection between language teacher characteristics (albeit a very limited set) and student achievement was that of Politzer \& Weiss (1969). They found very few direct relationships and deduced that flexibility was the key to successful teaching. On the basis of that study, Politzer (1970) concluded that the efficacy of teacher behaviours is dependent upon the teachers' ability to accurately judge the appropriateness of their actions or reactions. In a similar vein, Wong-Fillmore (1985) conducted a qualitative study of several elementary classrooms in which she found that teachers of the students with limited English proficiency who made the most progress in a year were those who tailored their language to the proficiency levels of their students. "They were effective communicators, I think, because all of them were concerned with communication" (43).

It is often assumed that experience in teaching ESL serves to develop and enhance the communicative skills required to accurately 
judge NNSs comprehension levels. Dahl (1981) compared experienced ESL teachers with naive NSs. She examined seven variables in the transcripts of her two subject groups addressing NNSs and found only one significant difference: the explicitness of requests was greater in naive NS speech. Unfortunately, Dahl did not look at NS-NS dyads on this measure, which would have provided a baseline against which it could be determined whether the difference in explicitness was a result of an adjustment for NNSs or merely an idiosyncratic feature of the speech of some of the subjects.

In a follow-up experiment, Dahl found that NNSs rated the teachers' instructions as easier to understand than those of the non-teachers; however, quantifying the crucial differences in experienced and inexperienced subjects' speech was not a straightforward task. Dahl hypothesized that an exaggerated intonation contour and better organization of information may have contributed to the teachers' higher ratings, but she made no measurements in either area. In sum, though teachers were rated as more comprehensible than non-teachers, none of Dahl's measures provided unequivocal evidence of differences in adjustments that were attributable to experience.

In a comparison of experienced and inexperienced teachers, Pica \& Long (1986) also found very few quantifiable differences. Experienced teachers used relatively more WH questions than did inexperienced ones, and the experienced teachers were more fluent. There were also more other-repetitions (that is, repetitions of the learners' output) in the experienced teachers' speech. With the exception of these few differences, however, Pica \& Long concluded that, as far as linguistic behaviour in the classroom is concerned, 'the influence of classroom context is strong enough to outweigh the effects of teaching experience' (p.96).

Clearly there is a range of sensitivity to NNSs' comprehension; this study is an attempt to identify the role of personality traits and experience in relation to communicative success, using controlled comparisons in which setting and task are held constant.

\section{Method}

\section{Subjects}

The subjects were eight ESL instructors, all of whom had a minimum of three years' teaching experience, and eight inexperienced speakers, that is, individuals who had had little or no contact 
with NNSs. All of the subjects (hereafter called narrators) were university educated speakers of standard Canadian English.

Each narrator was matched with a same-sex NS (for baseline data purposes) and a same-sex NNS in counterbalanced order, i.e., half the narrators were paired first with the NNSs while the other half met the NSs first.

The NNS participants were 12 Vietnamese, 3 Chinese and 1 Romanian, who were selected from level one (advanced beginner) classes; all had a minimum of nine years of education in their first language and none had much opportunity to use English outside of the classroom. The participants were not acquainted with their partners prior to the study.

Tasks

Film task.

Each narrator was asked to view a six minute, wordless animated film entitled The Spring and Fall of Nina Polanski (Hutton and Roy, 1974). This film was chosen because, in a federally commissioned study of films for ESL students (Smith, 1982) it had been well received and understood by several beginner ESL classes. A second reason for selecting this film was its inclusion of unexpected, somewhat startling sequences, such as the sudden appearance of children (one pops out of the dishwater) and the change in Nina's body (her torso turns into a number of household appliances). These scenes can be described with vocabulary and structures that are within low proficiency students' comprehension abilities. However, the odd quality of the scenes placed demands on the narrators because they could not rely heavily on the listeners' background knowledge or upon context to ensure comprehension.

Prior to viewing the film, each narrator was shown a list of comprehension questions (see Appendix). It was explained that he or she would be asked to tell the film's story to two partners independently, and that the partners would then be asked to respond to these same questions. The narrator was shown the questions again after viewing the film, then he or she was taken to another room where the first partner was waiting. The participants had a few minutes to get acquainted, after which they undertook an interaction task for approximately five minutes. The narrator was then asked to tell the listener the story of the film. The listener was advised that he or she would be questioned later. Interviews were conducted after the film task; listeners were given ample opportunity to answer the comprehension questions and were encouraged to expand where necessary. Both the task and the 
interviews were tape recorded. Each tape was subsequently transcribed in standard orthography.

Jackson personality inventory.

Narrators were asked to complete the Jackson Personality Inventory (JPI) (Jackson, 1976), either directly after meeting with their partners or within a few days. The inventory, which consists of 320 true/false questions, provides a standardized personality profile for each subject encompassing the following traits: anxiety, breadth of interest, complexity, conformity, energy level, innovation, interpersonal affect, organization, responsibility, risk-taking, self esteem, social adroitness, social participation, tolerance and value orthodoxy. This personality measure was selected because it is standardized for use on 'populations of average or above average ability' (Jackson, 1976, p.9), and because of its emphasis on interpersonal and social factors.

\section{Measures}

Conversational adjustments.

The subjects' narratives were coded according to Long's (1980a) criteria for the following adjustments: confirmation checks, comprehension checks, other-repetition, self-repetition, and clarification requests. The following information-seeking questions were also coded: yes/no questions, WH questions, and or-choice questions. In addition, the transcripts were coded for instances of paraphrase, imperatives and topic-dislocation, i.e., utterances in which new information appears at the beginning of the sentence, e.g., $A$ refrigerator she would look like. Adjustments were expressed as a percentage of the total number of words used by the narrator.

\section{Word frequency.}

The narratives were coded in their entirety for word frequencies based on the Thorndike \& Lorge (1944) word count. In a comparison of another count of the most frequently occurring words in adult spoken English (Wepman \& Lozar 1973) it was found that over $89 \%$ of the spoken English corpus was classified by Thorndike \& Lorge as occurring at least 100 or more times per million words. ${ }^{2}$ This suggests that despite certain obvious flaws (e.g., lack of morphological information, written corpus, datedness) the Thorndike \& Lorge count adequately represents frequency. Words were then classified as belonging to one of the count's following categories: the 500 most frequent words; the 1,000 most frequent words; words occurring 100 or more times per million; words 
occurring between 50 and 99 times per million; words occurring 26-49 times per million and words occurring 0-25 times per million.

\section{Speech rate.}

Overall rate (a combination of articulation rate and pauses) was determined by timing the narratives. The times were then divided by the number of words produced by each narrator to obtain a words-per-second measure.

\section{Scoring}

The NS and NNS listeners' answers to the comprehension questions were marked (acceptable answers appear in the Appendix); all the narrators successfully transmitted the story to their NS partners. The NNSs' comprehension scores are referred to as the narrators' communicative success.

The responses to the JPI were scored and transferred to a profile to obtain standardized scores.

\section{Analyses and Results}

\section{Personality Groupings}

Each narrator's standardized JPI scores were entered into Clustan, a cluster analysis programme. Clustan separates cases 'into groups such that the degree of association is high between members of the same group, and low between members of different groups' (Wishart, 1978, p.1). The analysis divided subjects into three groups. When the mean film success score for each group was compared against the mean score on each personality scale, it was found that the three factors of interpersonal affect, social participation, and organization varied in the same direction as communicative success. Additional Clustan analyses were done on all possible combinations of these three variables. There were two considerations in the final choice for personality grouping: 1) the strongest differentiation possible in terms of success and 2) relatively equal groups (for statistical purposes). The interpersonal affect/social participation ratings satisfied both criteria in that the groups were almost equal (high interpersonal affect/social participation, $n=9$; low interpersonal affect/social participation, $\mathrm{n}=7$ ) and the difference between mean success scores was substantial (24.9\%). Jackson (1976) describes a high scorer on the interpersonal affect trait as one who 'tends to identify closely with other people and their problems and who values close emotional ties with others', while a person who scores high on the social 
participation scale is an individual who 'will eagerly join a variety of social groups, values positive interpersonal relationships and is actively social.'

T-tests for independent means were calculated to determine whether or not ESL instructors and the inexperienced native speakers differed significantly on any of the personality variables. There were no significant differences between the two groups.

\section{Communicative Success}

A repeated measures ANOVA with listeners as the within factor, experience group as the between factor and success as the dependent variable indicated that there was no significant difference in communicative success between teachers and inexperienced NSs.

To determine whether there were differences in communicative success when narrators were grouped according to personality characteristics, another repeated measures ANOVA was carried out. A significant group by listener interaction $(F(1,14)=5.4, p=.04)$ and a subsequent Scheffe test ${ }^{3}$ on the interpersonal affect/social participation success means revealed that although both high and low groups were significantly more successful talking to NSs than the low interpersonal affect/social participation group talking to NNSs $\left(F^{\prime}=30.38, p<.05 ; F^{\prime}=30.25, p<.05\right.$ repectively), there was no significant difference between the high interpersonal affect/social participation group talking to NNSs and both groups paired with NSs. In other words, the two personality groups differed only with respect to their success in speaking to NNSs.

\section{Conversational Adjustments}

A Wilcoxin test was used to compare the conversational measures made for NS and NNS listeners. Across all narrators there were significantly more comprehension checks $(\mathrm{z}=3.71 ; \mathrm{p}<.005)$, self-repetition $(\mathrm{z}=2.81 ; \mathrm{p}<.005)$ and paraphrase $(\mathrm{z}=3.89 ; \mathrm{p}<.005)$ addressed to NNS partners. None of the 11 adjustments correlated significantly with communicative success scores.

A repeated measures ANOVA on the total adjustments and a subsequent Newman-Keuls test showed that teachers used significantly more adjustments per 100 words with NNSs than did the inexperienced NSs $(\mathrm{F}(2,21)=5.15, \mathrm{p}=.015){ }^{4}$

A repeated measures ANOVA with interpersonal affect/social participation groups as the between factor, listeners as the within factor and total adjustments as the dependent variable showed only a significant listener effect $(\mathrm{F}(1,14)=30.66, \mathrm{p}=.0001)$; in other 
words, NNS listeners elicited more adjustments than did NS listeners. However, there were no differences between the two personality groups.

\section{Word Frequency}

Separate repeated measures ANOVAs were done with the instructor and inexperienced speaker groups as the between factor, listener as the within factor and each of the word frequency categories as the dependent variables. Overall, whether the listener was a NS or a NNS had a significant effect. The 500 most frequent words $(\mathrm{F}(1,21)=14.733, \quad \mathrm{p}<.001)$, the top 1000 words $(\mathrm{F}(1,21)=18.65, \mathrm{p}<.001)$, words in the $100+$ per million range $(\mathrm{F}(1,21)=26.94, \mathrm{p}<.001)$, words in the $50-99$ per million range $(\mathrm{F}(1,21)=7.05, \mathrm{p}=.015)$ and least frequent words in the 0.25 per million range $(\mathrm{F}(1,21)=24.95, \mathrm{p}<.001)$ all differed significantly for NS versus NNS listeners. As might be expected, overall, narrators used more words in the frequent categories and fewer in the less frequent categories when speaking to NNSs. There were no significant differences in lexical choice between ESL instructors and inexperienced native speakers in any of the word frequency categories.

T-tests of the adjustments in word frequency for NNSs versus NSs were calculated on each of the measures for both personality groups. The high interpersonal affect/social participation group used significantly more of the top 500 words with NSSs $(t(8)=2.34$, $\mathrm{p}=.047$ ) and significantly fewer of the least frequent words $(\mathrm{t}(80)=2.71, \mathrm{p}=.027)$. There were no significant adjustments of word frequency in the low interpersonal affect/social participation group. Pearson correlation coefficients were calculated to examine the relationship between measures of word frequency adjustment for all narrators and the communicative success scores. Only the category $100+$ occurrences per million correlated significantly with success $(\mathrm{r}(1,14)=.55, \mathrm{p}=.026$, two-tailed $)$.

\section{Rate}

A repeated measures ANOVA with group (experienced vs. inexperienced narrators) as the between factor and listeners as the within term showed no group differences in overall rate and no group by listener interaction, although there was a significant listener effect $(F(1,14)=7.31, p=.017)$, i.e., there was a decrease in speech rate directed to NNS listeners.

A repeated measures ANOVA for rate with the high and low interpersonal affect/social participation groups as the within subjects 
factor indicated that there was a significant listener difference $(\mathrm{F}(1,14)=11.62, \mathrm{p}=.004)$ and a significant group by listener interaction $(F(1,14)=5.11, p=.04)$. A Scheffé test indicated that both high and low rated groups had significantly faster rates when talking to NSs (X=2.61 and 2.51 , respectively) than the low interpersonal affect/social participation group's rate when addressing NNSs $(X=1.96)\left(F^{\prime}=22.32, p<.1 ; F^{\prime}=15.76, p<.1\right)$. The rate used by the high interpersonal affect/social participation group to the NNSs $(X=2.5)$ did not differ significantly from the other rates.

A Pearson correlation of success scores and the subjects' rate of speech was nonsignificant at $\mathrm{r}(14)=.37, \mathrm{p}=.16$ (two-tailed) (note that the direction of the correlation is positive, contrary to expectation).

\section{Discussion}

The influence of ESL teaching experience and the personality traits of interpersonal affect and social participation on communicative success has been examined in relation to the use of conversational adjustments, word frequency and speech rate. The linguistic bchaviour of the two personality groups differed in a number of respects, whereas experienced and inexperienced narrators differed only in terms of conversational adjustments. The analysis of the communicative success scores indicated a) there was no difference when the subjects were grouped according to experience and b) that low interpersonal affect/social participation individuals had significantly more trouble communicating with a NNS than either group did in talking to a NS, while the high interpersonal affect/social participation group did not.

\section{Conversational Adjustments}

When the frequency of conversational adjustments utilized by experienced and inexperienced narrators was compared, it was found that teachers used a significantly higher percentage of adjustments than did the inexperienced NSs. However, when the subjects were grouped according to personality, no differences between the two groups emerged. Furthermore, none of the adjustments correlated significantly with communicative success.

The finding that there were no significant correlations of success with the total amount of conversational adjustment is not altogether surprising, given Long's suggestion (1983) that conversational adjustments serve multiple functions. He points out that they are sometimes used to avoid communication problems (strategies), to make repairs when there has been a communication failure (tactics), 
or some combination of the two. Simply determining the relative frequency of adjustment does not reveal whether a given adjustment is appropriate or that it has actually served a beneficial purpose. Conversational adjustments can improve communication if and only if the speaker can a) identify at which points they are needed, b) make the adjustment called for and c) ensure that the NNS has understood. To illustrate, one subject made several comprehension checks (italics indicate rising intonation) but didn't wait for the NNS's response to them. For example:

$\mathrm{NS}_{1}$ : Okay, I'm going to tell you generally what happened. It's the story about a woman from when she was young, when she gets married, when she has a baby and family, okay? you with me? and then her kids go away to school and she doesn't have anything to do with them again. . .

2

$\mathrm{NS}_{1}$ : Okay, so it's like your wife, okay, and she starts out, and she's in a garden. Do you understand a garden? Where there's flowers and trees, okay? birds? and she's walking and you can hear the birds singing and she's got a flower, and she's going (gesture) with the petals. Okay and the next scene that you see, okay, the next thing you see, she's married. Okay? she's getting married, there's a wedding ceremony and you see a picture of her and her husband? You see a picture of her mum and her dad and her aunt, you understand? Her family? Okay?

NNS: Oh.

$\mathrm{NS}_{1}$ : Okay, her mum and her dad and her aunt. And in the wedding ceremony, they cut, oh they cut the cake? Okay?

NNS: Cut?

$\mathrm{NS}_{1}$ : Yeah, the wedding cake, okay? and that's about all you see of the wedding, okay?. .

3

$\mathrm{NS}_{1}$ : So when she waves goodbye to her kids, okay? and she walks along, she's walking out of the house, the fridge, the stove, the washing machine fall off, okay? They 
aren't part of her anymore. Okay? (laugh) Yeah it's a little crazy, but that's what happens in the movie.

4

$\mathrm{NS}_{2}$ : It shows the three children going to school, leaving the house. And, once the children have gone, many years have passed. Do you understand? Many years have gone by, she's, the children have grown up, they've gone to school. And then, she walks through the house, and goes outside, goes back to the forest, where she started. Where she started, in the beginning, in the forest, picking flowers.

It is conceivable that the listeners sometimes provided these NS interlocutors with nonverbal cues of comprehension, thus eliminating the need for the narrators to clarify or check comprehension further; however these same listeners are the ones who understood the least overall. Note, too that the NS in example 2 did not give a very satisfactory response to the learner's confirmation check. The following examples are also indicative of failures to respond adequately to the learners.

$\mathrm{NS}_{2}: \ldots$ and then she has more children, finally she has three children.

NNS: three children?

$\mathrm{NS}_{2}$ : And the movie shows her life in the house. Doing household chores. .

NNS: Where's she got the tree?

$\mathrm{NS}_{3}$ : Pardon?

NNS: What is the tree, the tree in the park or somewhere? Or in the beside the house?

$\mathrm{NS}_{3}$ : Well it's hard to say.

NNS: Oh.

$\mathrm{NS}_{3}$ : I'm not sure. It's just a little, it's just a little movie and there's no words in the movie. So there's just pictures.

Contrast these excerpts with the following: 
$\mathrm{NS}_{4}: \quad \ldots$ She's a bride. She's all dressed in white. You know what a bride is?

NNS: Bride?

$\mathrm{NS}_{4}$ : A bride. A bride is a woman on her wedding day, when she has her, her white dress on and her special veil.

NNS: yeah I know

8

$\mathrm{NS}_{4}: \quad \ldots$ There's part of the film where she, she turns into a fridge. You know what a fridge is?

NNS: fridge?

$\mathrm{NS}_{4}$ : A refrigerator? You know, in the kitchen we have a refrigerator? That you put the milk in and the eggs.

NNS: Ah, yeah, yeah, I know, I know, yeah I know.

9

$\mathrm{NS}_{5}: \quad \ldots$ If she was standing by the stove, her body would look like a stove.

NNS: Why?

$\mathrm{NS}_{5}$ : I'm not sure, but I think it could be, I think it could be that she was working so hard, always working in the kitchen, by the fridge, by the stove, that that's all she felt like.

NNS: yeah

$\mathrm{NS}_{5}$ : She felt-I'm not really a woman, I'm just a fridge or a stove. Do you understand?

NNS: Yeah

Clearly, to assess the contribution of individual conversational adjustments (and their relationship to personality traits), a fine-grained evaluative analysis is required, perhaps using Hawkins (1985) post-interview technique in which both participants listen to a tape recording of their exchange and comment on what they understood or perceived at each stage of the interaction.

It should be noted that Derwing (1987) found a significant difference in the type of adjustments used by experienced and inexperienced subjects in a two-way interaction task (Spot the Difference). Teachers made extensive use of comprehension checks, confirmation checks, WH questions and clarification requests, all of which require feedback from the NNS listener. Inexperienced subjects, on the other hand, used significantly greater percentages of only two adjustments which elicit a NNS response: yes/no questions and comprehension checks. Although the teacher-NNS 
pairs did not perform better on the task than the inexperienced NS-NNS pairs, it appeared that teachers were making a greater effort to draw the NNS into the interaction. Evidence of comprehension success need not be the only indicator of useful communicative experiences. Since it may be as important to produce L2 in a comprehensible manner as it is to understand it in order to achieve a relatively high proficiency (Swain, 1985), the conversational adjustments of the experienced narrators may indeed benefit the NNSs. ${ }^{5}$ Unfortunately, it seems that this behaviour is context-bound (cf. Pica \& Long, 1986): other researchers have found the classroom to be lacking in opportunities for negotiation. Many programmes which purport to follow a communicative approach to language teaching in fact adhere to traditional, teacher-fronted, teacher-dominant forms of instruction in which little true communication takes place (Spada, 1986; Iglesias, 1985).

\section{Word Frequency}

Although there were no differences in word frequency adjustment between experienced and inexperienced narrators, high interpersonal affect/social participation narrators made significantly more adjustments in two categories of lexical frequency-more words in the top 500 class, and fewer words in the least frequent class - than did their low interpersonal affect/social participation counterparts. That the two adjustments are not significantly correlated with success was presumably because a) the relative frequency of the lexical items addressed to NSs was also extremely high on this task (thus the adjustments, although consistent, were small) and b) the number of words in the two categories was quite limited. To determine whether the high interpersonal affect/social participation narrators' tendency to adjust more for NNSs is really beneficial, an experiment is called for in which lexical frequency is controlled.

\section{Rate}

There was no difference between the experienced and inexperienced groups in their adjustment of speech rate, that is, there was a significant reduction in rate addressed to NNSs in both narrator groups. Conversely, rate of delivery proved to be another distinction between the high and low interpersonal affect/social participation groups. High interpersonal affect/social participation subjects did not generally slow down for their NNS partners, while low interpersonal affect/social participation subjects did. Interestingly enough, Derwing (1990) found that successful subjects in this task did not adjust their rate (despite their intuitions that 
they had), while less successful communicators slowed down. Moreover, the change in speech rate was found to be a result of increased pause time rather than a slowed articulation rate. The following example (the numbers in parentheses represent the length of pauses in seconds) indicates that this low interpersonal affect/social participation subject experienced considerable difficulty when talking to her NNS partner:

$\mathrm{NS}_{6}$ : And (8.1) and it, I guess she spends all her time looking after the children and doing the household.

NNS: Uh huh

$\mathrm{NS}_{6}$ : The the work in the house, and in the movie, they show this, (1.) because, uh (6.1) they show her turning into a stove (1.5) and a, and a refridger, a fridge, (1.2) and a sink, like, so (4.2) it's a weird movie. But basically I think what they're trying to say is that (1.9) her children only see her as a person who looks after them and gives them their food and washes their clothes and things.

It is not clear, then, whether the rate change overall was an adjustment to facilitate NNS comprehension as is commonly assumed, or a symptom of communicative difficulties (cf. Griffiths, 1990). This is not a suggestion that high interpersonal affect/social participation speakers never alter rate when talking to NNSs. Such speakers may simply be more sensitive to the linguistic needs of their interlocutors and so tend to slow down only when necessary, i.e., when a combination of other conversational adjustments is insufficient.

\section{Conclusion}

As Wesche and Ready (1985) have pointed out, individual speech styles have a tremendous influence on the nature and degree of adjustment that individuals make for NNSs. These differences become interesting from a theoretical viewpoint if groups of people can be shown to share certain characteristics. The common perception that the best ESL teachers are the friendly, sympathetic and good natured ones may have some basis in fact. The reasons for this may not be related to the pervasive view that it is the knowledge that these people 'care' that promotes learning in a second language student. Perhaps high interpersonal affect/social participation speakers pay more attention to what their inter- 
locutors do and do not say, and this leads them into true interactions, negotiating where necessary, rather than engaging in thinly disguised monologues. An awareness of the NNS's linguistic capabilities, such as the recognition of a lack of comprehension, is a prerequisite to making adjustments that are appropriate to the situation at hand, as well as leading to the rejection of adjustments that are not actually required.

The last few years have witnessed an increased interest in defining the discourse features within the ESL classroom (e.g., Early, 1987) as well as efforts to identify their efficacy (e.g., Long 1985; Pica, Doughty \& Young, 1986). It is critical that research continue to identify features of successful NS-NNS interaction from multiple standpoints. Eventually these studies will contribute to a better understanding of the nature of discourse in general and the needs of language learners in particular. This preliminary study identified a combination of two personality traits which appear to correlate with successful communication with low proficiency NNSs. There is a need to explore this connection further. A finding that consistent behaviours beneficial to NNS comprehension are associated with a given personality profile would not by any stretch of the imagination imply the need for a screening of prospective ESL instructors; rather, it would suggest the need for an emphasis on communication skills in teacher training programmes. Current TESL education programmes tend to concentrate on second language acquisition, competing methodologies, materials design, etc.; they do not generally address the issue of how to talk to a low proficiency NNS-that problem is left up to the novice's intuitions on the first day of class. Those individuals who are naturally sensitive to the communicative needs of their interlocutors will cope, while those who aren't could benefit from some guidance. 


\section{NOTES}

1. See the section below entitled Personality Groupings for an explanation of the choice of traits to be tested.

2. The Wepman \& Lozar corpus was not used in this study because it is limited to fewer than 400 words.

3. Because of unequal $n$ 's (high interpersonal affect/social participation $=9$; low interpersonal affect/social participation $=7$ ), a Scheffé test was applied. The significance level was set at .10 as suggested by Scheffe (1959) to offset the conservatism of the test.

4. A third group of eight NNS narrators not reported here was included in this ANOVA; therefore the degrees of freedom are greater than in the ANOVAs in which only two groups of narrators were compared.

5. In fact, Pica (1988) found that learners are able to produce utterances that are more target-like in response to confirmation checks and clarification requests; however, there is a strong tendency for NSs to model the target form for their NNS interlocutors rather than pressing them to adjust their production.

\section{ACKNOWLEDGEMENTS}

My appreciation goes to Judy Cameron, who assisted in all aspects of the study. I would like to thank the staff and students at AVC Edmonton for their participation. I also wish to acknowledge the financial support of the Social Sciences and Humanities Research Council. 


\section{APPENDIX}

These questions were shown to the narrators both prior to and immediately after they viewed the film. It was explained to them that their interlocutors would be required to answer these questions. The narrators were not shown the answers.

\section{Comprehension Questions}

1. Who is the story about?

2. Where does the story begin?

3. What happens after the woman gets married?

4. What is the woman doing when she has her first baby?

5. What happens to the woman after several years of working in the house and having children? What happens to her body?

6. What does the woman do after the children go to school?

\section{Answers}

1. Nina/a woman/a girl

2. In a garden/forest/park

1 point

3. She does housework

1 point

She has children

1 point

4. She's washing dishes

5. Her body turns into a fridge/stove/etc.

1 point

1 point

6. She goes back to the garden

1 point

She sits among the leaves/it's fall/autumn

1 point

1 point

\section{REFERENCES}

Dahl, D.A. (1981). The role of experience for speech modifications for second language learners. Minnesota Papers in Linguistics and Philosophy of Language, 7, 78-93.

Derwing, T.M. (1987). Individual differences in foreigner talk. Ph.D. Dissertation, University of Alberta.

Derwing, T.M. (1990). Speech rate is no simple matter: rate adjustment and NS-NNS communicative success. Studies in Second Language Acquisition, 12, 303-313.

Early, M. (1987). Linguistic input and interaction in the content classroom. TESL Canada Journal, 4, 41-58. 
Gaies, S.J. (1982). Native speaker-nonnative speaker interaction among academic peers. Studies in Second Language Acquisition, 5, 74-81.

Gass, S.M. \& Varonis, E.M. (1984). The effect of familiarity on the comprehensibility of nonnative speech. Language Learning, 34, 65-89.

Griffiths, R. (1990). Speech rate and NNS comprehension: a preliminary study in time-benefit analysis. Language Learning, 40, 311-36.

Hawkins, B. (1985). Is an 'appropriate response' always so appropriate? In S.M. Gass \& C.J. Madden (Eds.), Input in Second Language Acquisition (pp. 162-178). Rowley, MA: Newbury House.

Hutton, J. \& Roy, L. (1974). The spring and fall of Nina Polanski. Montreal: National Film Board of Canada and agencies of the Government of Canada.

Iglesias, A. (1985). Cultural conflict in the classroom: the communicatively different child. In D.H. Ripich \& F.M. Spinelli (Eds.), School discourse problems (pp. 75-96). San Diego: College Hill Press.

Jackson, D.N. (1976). Jackson personality inventory (manual). Goshen, New York: Research Psychologists Press.

Larkin, J. E. (1987). Are good teachers perceived as high self monitors? Personality and Social Psychology Bulletin, 13, 64-72.

Long, M. H. (1980a). Input, interaction and second language acquisition. Ph.D. Dissertation, UCLA.

Long, M. H. (1980b). Inside the 'black box': methodological issues in classroom research on language learning. Language Learning, $30,1-42$.

Long, M.H. (1983). Native speaker/non-native speaker conversation and the negotiation of comprehensible input. Applied Linguistics, 4, 126-141. 
Moscowitz, G. (1978). Caring and sharing in the foreign language class. Rowley, MA: Newbury House.

Pica, T., Doughty, C. \& Young, R. (1986). Making input comprehensible: do interactional modifications help? I.T.L. Review of Applied Linguistics, 72, 1-25.

Pica, T. \& Long, M.H. (1986). The classroom and linguistic performance of experienced and inexperienced ESL teachers. In R.R. Day (Ed.), Talking to Learn (pp. 85-98). Rowley, MA: Newbury House.

Pica, T. (1988). Interlanguage adjustments as an outcome of NS-NNS negotiated interaction. Language Learning, 38, 45-73.

Politzer, R.L. \& Weiss, L. (1969). Characteristics and behaviors of the successful foreign language teacher. Stanford: Stanford Centre for Research and Development in Teaching: Technical Report No. 5.

Politzer, R.L. (1970). Some reflections on 'good' and 'bad' language teaching behaviors. Language Learning, 20, 31-43.

Scheffe, H. (1959). The analysis of variance. New York: John Wiley.

Smith, I. (1982). Teaching English as a second language with the aid of selected films. Montreal: National Film Board of Canada.

Spada, N. (1986). The interaction between type of contact and type of instruction: some effects on the L2 proficiency of adult learners. Studies in Second Language Acquisition, 8, 181-200.

Stevick, E.W. (1974). Language instruction must do an about-face. Modern Language Journal, 58, 379-384.

Swain, M. (1985). Communicative competence: some roles of comprehensible input and comprehensible output in its development. In S.M. Gass \& C.J. Madden (Eds.), Input in Second Language Acquisition (pp. 235-253). Rowley, MA: Newbury House. 
Thorndike, E. \& I. Lorge (1944). The teacher's word book of 30,000 words. New York: Columbia University Teachers College.

Warren-Leubecker, A. \& Bohannon, J.N. (1982). The effects of expectations and feedback on speech to foreigners. Journal of Psycholinguistic Research, 11, 207-215.

Wepman, J.M. \& Lozar, B. (1973). The most frequently used words in spoken English. Journal of Psycholinguistic Research, 2, 129-136.

Wesche, M.B. \& Ready, D. (1985). Foreigner Talk in the university classroom. In S.M. Gass \& C.J. Madden (Eds.), Input in Second Language Acquisition (pp. 89-114). Rowley, MA: Newbury House.

Wishart, D. (1978). Clustan user manual. Edinburgh: Edinburgh Program Library Unit.

Wong-Fillmore, L. (1985). When does teacher talk work as input? In S.M. Gass \& C.J. Madden (Eds.), Input in Second Language Acquisition (pp. 17-50). Rowley, MA: Newbury House.

Zuengler, J. (1989). Performance variation in NS-NNS interactions: ethnolinguistic difference or discourse domain? In S.M. Gass, C. Madden, D. Preston \& L. Selinker (Eds.), Variation in second language acquisition Volume 1: Discourse and Pragmatics (pp. 228-244). Clevedon: Multilingual Matters.

\section{THE AUTHOR}

Tracey Derwing is an assistant professor in the Department of Adult, Career and Technology Education at the University of Alberta. Her research interests include aspects of NS-NNS discourse, NNS listening comprehension, communication in the workplace, and adult L2 literacy. Tracey has also had a longterm involvement in citizenship issues for immigrants; she is currently the chair of the TESL Canada SIG for citizenship education. 